\title{
Oxygen gradients affect behaviour of caged Atlantic salmon Salmo salar
}

\author{
Tina Oldham ${ }^{1, *}$, Tim Dempster ${ }^{2}$, Jan Olav Fosse ${ }^{3}$, Frode Oppedal ${ }^{3}$ \\ ${ }^{1}$ Aquatic Animal Health Group, Institute for Marine and Antarctic Studies, University of Tasmania, Launceston, \\ Tasmania 7250, Australia \\ ${ }^{2}$ Sustainable Aquaculture Laboratory - Temperate and Tropical (SALTT), School of BioSciences, University of Melbourne, \\ Parkville, Victoria 3052, Australia \\ ${ }^{3}$ Institute of Marine Research, Matredal 5984, Norway
}

\begin{abstract}
Dissolved oxygen (DO) conditions in marine aquaculture cages are heterogeneous and fluctuate rapidly. Here, by temporarily wrapping a tarpaulin around the top 0 to $6 \mathrm{~m}$ of a marine cage $\left(2000 \mathrm{~m}^{3}\right)$, we manipulated DO to evaluate the behavioural response of Atlantic salmon Salmo salar to hypoxia. Videos were recorded before, during and after DO manipulation at $3 \mathrm{~m}$ depth while vertical profiles of temperature, salinity, DO and fish density were continuously measured. The trial was repeated 4 times over a 2 wk period. Temperature and salinity profiles varied little across treatment periods; however, DO saturation was reduced at all depths in all replicate trials during the tarpaulin treatment compared to the periods before or after. In 3 out of 4 trials, swim speeds were 1.5 to 2.7 times slower during the tarpaulin treatment than the before or after periods. Significant changes in vertical distribution of fish density and DO were observed between treatment periods in all replicate trials; salmon swam either above or below the most hypoxic depth layer (59 to $62 \%$ DO saturation). In a regression tree analysis, the relative influence of DO in determining fish distribution was $17 \%$, while temperature $(39 \%)$ and salinity $(44 \%)$ explained the majority of variation. Our results demonstrate that salmon are capable of modifying their distribution and possibly activity levels in response to intermediate DO levels, but that DO is not a primary driver of behaviour at the saturation levels examined in this study.
\end{abstract}

KEY WORDS: Hypoxia · Dissolved oxygen · Behaviour · Salmo salar · Fish distribution · Aquaculture

\section{INTRODUCTION}

The energy yield of anaerobic glycolysis is only $10 \%$ that of aerobic metabolism (Hochachka \& Somero 2014), thus animals depend on a consistent supply of oxygen from their surroundings to achieve optimal performance. In the aquatic environment however, where diffusion happens slowly and photosynthesis can only partially meet the metabolic demands of organisms in the surface waters (Richards et al. 2009), dissolved oxygen (DO) concentration varies both vertically and horizontally with changing light, temperature, currents (Johansson et al. 2007), wind and rainfall (Diaz 2001). For these reasons, DO

${ }^{*}$ Corresponding author: tina.oldham@utas.edu.au is a major limiting factor affecting the growth, distribution and survival of fishes.

Hypoxia, defined in the marine environment as a drop in DO saturation which reduces metabolic scope (Pollock et al. 2007, Richards et al. 2009), occurs naturally in coastal environments (e.g. Johannessen \& Macdonald 2009, Silva \& Vargas 2014, Brown et al. 2015). Poor DO conditions are exacerbated in aquaculture cages due to restricted water movement, nutrient loading and locally increased biomass (Johansson et al. 2006, 2007, Oppedal et al. 2011b, Burt et al. 2012), and are becoming more common as global temperatures rise (Gruber 2011). In extreme cases, acute hypoxia results in mass mortal-

() The authors 2017. Open Access under Creative Commons by Attribution Licence. Use, distribution and reproduction are unrestricted. Authors and original publication must be credited. 
ity (Thronson \& Quigg 2008, Stauffer et al. 2012); in less extreme cases, sub-optimal DO concentrations result in decreased growth, appetite, immune function, swimming performance and fish welfare (Oppedal et al. 2011a, Remen et al. 2012, 2014, Burt et al. 2013, Kvamme et al. 2013).

Fish utilize numerous strategies to mitigate the impacts of hypoxia, including physiological adjustments, morphological adaptations, molecular defences and behavioural modifications (Richards et al. 2009). The most immediate strategies to minimize acute hypoxic stress are behavioural adaptations such as avoidance, aquatic surface respiration, air breathing and altered activity levels (Kramer 1987). Many species of fish can actively avoid hypoxic conditions (Pihl et al. 1991, Wannamaker \& Rice 2000, Brown et al. 2015), but not all (Kramer 1987, Butler et al. 2001). For example, Atlantic cod Gadus morhua L. did not avoid extremely hypoxic conditions when a normoxic refuge was available (Herbert et al. 2011), whereas in a similar trial, rainbow trout Onchorhynchus mykiss displayed avoidance behaviour beginning at $80 \%$ DO saturation $\left(17\right.$ to $19^{\circ} \mathrm{C}$ ) (Poulsen et al. 2011). Even among fish that avoid reduced DO concentrations, the point at which behavioural responses are initiated varies greatly with species, lifestyle and habitat (Whitmore et al. 1960, Richards et al. 2009).

Uncertainty exists regarding the extent to which the world's most farmed marine fish, Atlantic salmon Salmo salar, respond behaviourally to hypoxia. One field trial which investigated the relationship between environmental parameters and vertical salmon distribution observed no consistent response to DO, despite reaching levels as low as $57 \%$ saturation (Johansson et al. 2006). However, an alternate study at 4 commercial farm sites found that salmon avoided specific depth ranges in the water column where lowest DO concentrations $\left(60 \%\right.$ saturation at $\left.15^{\circ} \mathrm{C}\right)$ occurred (Johansson et al. 2007). Given that DO concentrations reach severely hypoxic levels in commercial cages for extended periods of time (Oppedal et al. 2011a, Burt et al. 2012, Stien et al. 2012, Dempster et al. 2016), and that commercially viable mitigation options are limited (Bergheim et al. 2006, Srithongouthai et al. 2006, Oppedal et al. 2011b), it is critical to know whether salmon avoid hypoxic areas for farmers to maximize welfare and production performance.

Salmon in sea cages alter their distribution and behaviour in response to numerous stimuli, including light (Oppedal et al. 2007), temperature, salinity, feeding (Oppedal et al. 2011a), water current velocity (Johansson et al. 2014), sound (Bui et al. 2013) and sea lice infestation level (Bui et al. 2016). Given the myriad factors affecting salmon in sea cages, experimental testing within the marine cage environment is required to understand the behavioural trade-offs made by salmon in response to hypoxia and other environmental factors. Here, we manipulated DO levels within a sea cage to determine if salmon altered their behaviour to avoid areas of low DO concentration among the other environmental factors which control their vertical distribution.

\section{MATERIALS AND METHODS}

\section{Experimental setup}

The experiment was performed in a research scale $12 \times 12 \times 29 \mathrm{~m}$ marine cage at the Institute of Marine Research's Solheim cage environment laboratory, stocked at a density of $7.67 \mathrm{~kg} \mathrm{~m}^{-3}$ with 13428 (mean mass $=2.4 \mathrm{~kg}$ ) Atlantic salmon Salmo salar. At the 15 to $21 \mathrm{~m}$ depth band, below which the majority of fish were observed to aggregate during preliminary observations, a tarpaulin was permanently attached to the cage net to create a barrier to oxygen replenishment. To reduce DO below ambient levels and create a gradient, the entire net cage was raised by crane until the tarpaulin surrounded the upper 0 to $6 \mathrm{~m}$ depth band where fish schooled at high densities. During DO reduction periods, the total available cage depth was $14 \mathrm{~m}$ (Fig. 1) with a stocking density of $15.34 \mathrm{~kg} \mathrm{~m}^{-3}$. For each trial, data was recorded during 3 periods: 40 min prior to raising the tarpaulin (before), $60 \mathrm{~min}$ with the tarpaulin secured at the sur-

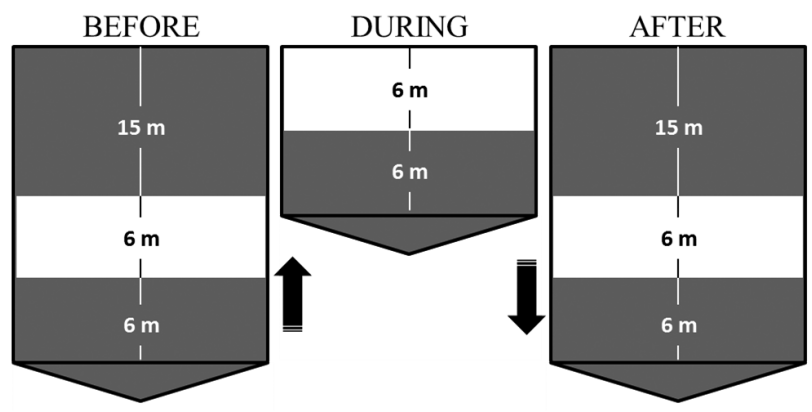

Fig. 1. Cage setup during each of the 3 dissolved oxygen reduction treatment periods: 'before' (control), 'during' (treatment) and 'after' (control). Throughout all trials and treatment periods, temperature, salinity and dissolved oxygen measurements were collected within the top 0 to $6 \mathrm{~m}$ of the cage. Vertical distribution of Atlantic salmon Salmo salar was estimated by calculating relative echo intensities within the uppermost $6 \mathrm{~m}$ depth band during each treatment period. The white band represents the position of the $6 \mathrm{~m}$ deep tarpaulin 
face (during) and $40 \mathrm{~min}$ after the tarpaulin was dropped (after). Four replicate trials were conducted between 30 October and 9 November 2015. All trials were performed in daylight between 09:00 and 16:00 $\mathrm{h}$ and were timed to co-occur with slack tide to avoid deformation of the cage.

Though data were collected throughout the entirety of the cage, all analyses were confined to the top 0 to $6 \mathrm{~m}$ depth band where the tarpaulin was located during treatment. This strategy was chosen to minimize the potentially confounding effect of the tarpaulin on fish behaviour. If the entire cage area was considered it would have been impossible to distinguish between a response to the reduced DO concentrations within the tarpaulin and a response to the tarpaulin itself. By focusing only on fish which were within the tarpaulin area, we were assured that any changes in distribution could be attributed to environmental variations and not as a result of a response to the tarpaulin.

During each replicate trial, water temperature, DO and salinity were continuously recorded by a CTD (SD204, SAIV AS) vertically profiling between 0 and $13 \mathrm{~m}$ at $0.6 \mathrm{~m} \mathrm{~min}^{-1}$ on an automated Belitronics winch. The CTD DO probe was calibrated prior to the start of each trial.

\section{Fish density measurements}

Vertical fish distribution was quantified as described by Bjordal et al. (1993) using an echo-integration system (Lindem Data Acquisition) connected to an upward-facing transducer with a $15^{\circ}$ acoustic beam positioned beneath the cage at a fixed depth of $30 \mathrm{~m}$. Echo intensity was recorded once per minute in $7 \mathrm{~cm}$ depth intervals from 0 to $29 \mathrm{~m}$. The sum of all echo intensity measurements between 0 and $6 \mathrm{~m}$ for each minute was then calculated and mean values of every $7 \mathrm{~cm}$ depth band were used to calculate relative echo intensity as a measure of percent fish biomass. Mean echo intensity values for each $0.21 \mathrm{~m}$ depth band between 0 and $6 \mathrm{~m}$ were calculated for all treatment periods (before, during, after).

\section{Swimming speeds}

Fish swimming speed was monitored using an underwater $360^{\circ}$ pan/tilt Orbit Subsea camera controlled from the surface by a winch. Videos during each treatment period were recorded at a depth of $3 \mathrm{~m}$. Instantaneous swimming speeds were calculated as body lengths per second (BL s${ }^{-1}$ ) based on the time required for the snout and tail of an individual to pass a vertical reference line within the cage (Dempster et al. 2008). Swimming speed was calculated for 20 individuals haphazardly chosen in each treatment period, totalling 240 individuals.

\section{Data analyses}

For each trial, differences in vertical distribution between treatment periods of temperature, salinity, DO saturation and fish density were tested for with 2-sample Kolmogorov-Smirnov tests. To correct for multiple comparisons, statistical significance $(\alpha=$ 0.05 ) was determined at a Bonferroni-corrected pvalue of 0.007 . Instantaneous swimming speeds were compared using repeated measures ANOVAs. Significant ANOVA results were further analysed using Tukey's HSD (honest significant difference) test for specific pair-wise comparisons.

To determine the relative influence of each environmental factor in explaining vertical fish distribution, data from all trials during the oxygen reduction period were pooled and fish density was modelled as a function of temperature, salinity and DO using a non-parametric regression tree method (Therneau \& Atkinson 1997, Johansson et al. 2006, 2007). Briefly, this involves identifying a single variable which best divides the data into 2 groups based on reduction of relative error. The data is separated and the same process repeated, separately, for each sub-group until no further improvements can be made. Cross-validation is then used to 'prune' the tree to the final model. In a graphical presentation, each split is seen as 1 stem dividing into 2 branches. The branch to the left is written out in the split, and the one to the right the opposite. Branch length is proportional to reduction in relative error. The 'leaves' at the end of each terminal branch are predicted fish density, scaled between 0 and 1 .

\section{RESULTS}

Throughout all trials, a consistent pycnocline was observed with a cool, brackish $\left(\sim 10^{\circ} \mathrm{C}, 20\right.$ ppt salinity) surface layer which transitioned to warmer seawater $\left(\sim 13^{\circ} \mathrm{C}, 30 \mathrm{ppt}\right)$ at a depth between 2 and $4 \mathrm{~m}$. Temperature and salinity varied little between treatment periods, whereas DO saturation was reduced by $10 \%$ on average during the tarpaulin treatment compared to the before and after periods in all replicate trials (Table 1). Fish density observations of the 
Table 1. Range and variation of environmental conditions experienced by Atlantic salmon Salmo salar throughout the dissolved oxygen reduction experiment. Before, during and after refer to the measurement period in relation to dissolved oxygen reduction treatment (see Fig. 1 and 'Materials and methods: Experimental setup' for details)

\begin{tabular}{|c|c|c|c|c|c|c|}
\hline Period & $\begin{array}{c}\text { Sample } \\
\text { size }\end{array}$ & Mean & $\begin{array}{l}\text { Standard } \\
\text { deviation }\end{array}$ & Range & Median & $\begin{array}{l}\text { Coefficient } \\
\text { of variation }\end{array}$ \\
\hline \multicolumn{7}{|c|}{ Temperature $\left({ }^{\circ} \mathrm{C}\right)$} \\
\hline Before & 87 & 12.2 & 1.1 & $10.2-13.5$ & 12.7 & 0.09 \\
\hline During & 116 & 11.6 & 1.1 & $9.9-13.4$ & 11.4 & 0.10 \\
\hline After & 116 & 11.6 & 1.4 & $9.6-13.6$ & 11.6 & 0.12 \\
\hline \multicolumn{7}{|c|}{ Salinity (ppt) } \\
\hline Before & 87 & 25.7 & 5.0 & $15.9-31.2$ & 27.8 & 0.20 \\
\hline During & 116 & 24.5 & 4.4 & $16.3-30.9$ & 23.4 & 0.18 \\
\hline After & 115 & 24.1 & 5.1 & $14.8-30.8$ & 24.1 & 0.21 \\
\hline \multicolumn{7}{|c|}{ Dissolved oxygen (\% saturation) } \\
\hline Before & 87 & 75.2 & 5.4 & $68.1-86.6$ & 72.9 & 0.07 \\
\hline During & 116 & 65.3 & 4.7 & $59.4-78.4$ & 64.4 & 0.07 \\
\hline After & 116 & 75.9 & 5.6 & $67.2-85.7$ & 75.2 & 0.07 \\
\hline
\end{tabular}

entire $29 \mathrm{~m}$ deep cage area found that, on average, $81 \%$ of the fish biomass swam shallower than $14 \mathrm{~m}$ prior to the tarpaulin being raised to the surface, and that total fish density was lower in the top 0 to $6 \mathrm{~m}$ during treatment than either before or after in all 4 trials. However, during all 4 trials, fish density in the 0 to $2 \mathrm{~m}$ surface band was higher during tarpaulin treatment than in either the before or after periods.

Analysis of variance tests on instantaneous swimming speeds detected significant variation between treatment periods in 3 of the 4 replicate trials $(F>$ 21.4, $\mathrm{p}<0.001)$. In all 3 cases, swimming speeds were 1.5 to 2.7 times slower $(\mathrm{p}<0.05)$ during the tarpaulin treatment (range: 0.35 to $0.36 \mathrm{BL} \mathrm{s}^{-1}$ ) than in the before or after periods $\left(0.53\right.$ to $0.95 \mathrm{BL} \mathrm{s}^{-1}$; (Fig. 2).

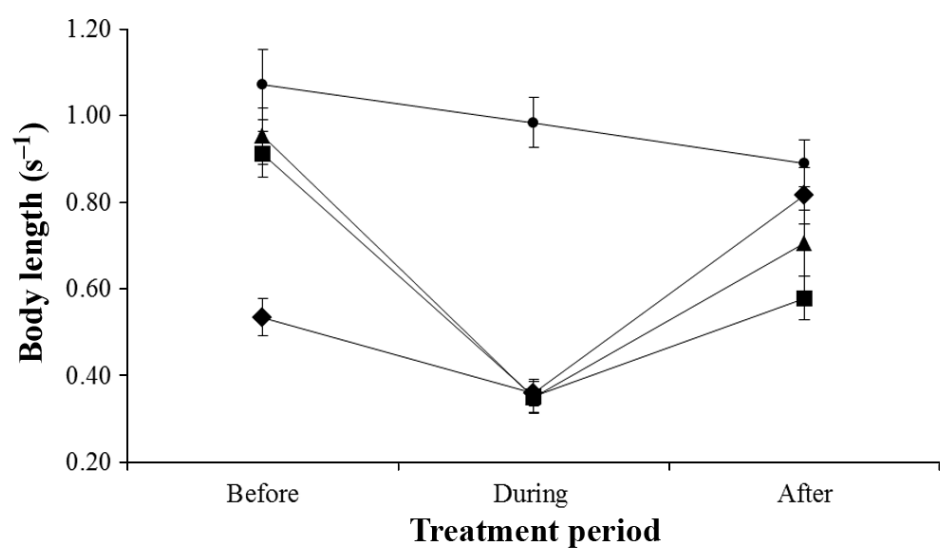

Fig. 2. Mean \pm SE instantaneous swimming speeds (body lengths per second; $\mathrm{BL} \mathrm{s}^{-1}$ ) of Atlantic salmon Salmo salar before, during and after dissolved oxygen reduction treatment. The 4 replicate trials

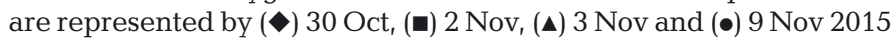

In the regression tree model, salinity and temperature had the largest relative influences on fish density, at 44 and $39 \%$ respectively, while DO was only $17 \%$. Node 1 of the tree, salinity $<28.47 \mathrm{ppt}$, explained the largest amount of variance; however, the surrogate split of temperature $<12.58^{\circ} \mathrm{C}$ had $97 \%$ agreement with the primary split, suggesting that both variables were critical drivers of salmon distribution within the cage. Of the 11 nodes in the tree, 4 splits were attributed to salinity, 5 to temperature and 2 to DO saturation (Fig. 3). The most preferred environment was salinity $>30.43 \mathrm{ppt}$, temperature $<13.14^{\circ} \mathrm{C}$ and DO saturation $>65.17 \%$. In both cases where DO saturation was attributed a split, higher levels of DO were the preferred condition.

\section{Trial 1}

Environmental conditions between periods were the most variable during Trial 1, with significantly different distributions in both salinity and temperature (Fig. 4). Vertical distribution of fish density also differed significantly during each of the measurement periods. In the period before the tarpaulin treatment, lowest fish density was observed at the surface and increased with depth. During the tarpaulin treatment, minimum fish density occurred at $1.8 \mathrm{~m}$ and markedly increased with depth to a maximum at $6 \mathrm{~m}$. In the period after the tarpaulin treatment, fish density distribution was bimodal with minimum density at the surface and maximum density peaks at 2 and $5.4 \mathrm{~m}$ (Fig. 5).

\section{Trial 2}

Temperature and salinity distributions did not differ significantly between any of the treatment periods (Fig. 4). Vertical distribution of fish biomass was similar during the before and after periods, with minimum fish densities occurring at the surface and increasing with depth. During the tarpaulin treatment, vertical fish distribution differed significantly from the period after, with minimum fish density occurring at $3 \mathrm{~m}$ and bimodal peak densities at 1 and $6 \mathrm{~m}$ (Fig. 5). 


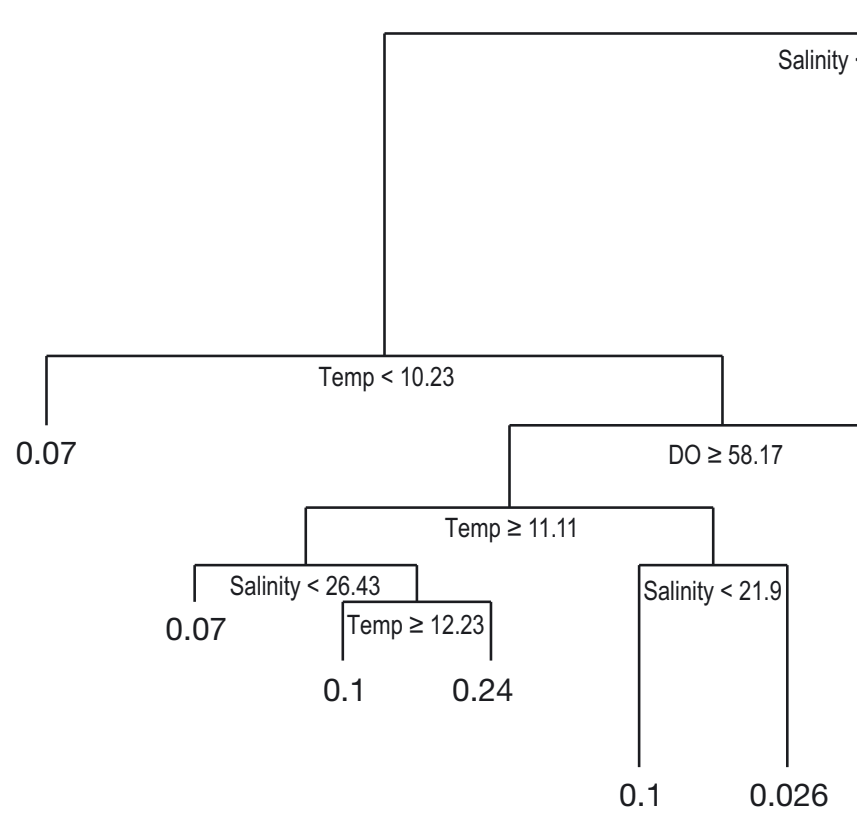

Trial 3

Temperature and salinity distributions were similar throughout all treatment periods (Fig. 4). Vertical distribution of fish biomass did not differ significantly during the before and after periods, with minimum fish densities occurring at the surface and maximum densities near $4 \mathrm{~m}$. During the tarpaulin treatment, vertical fish density distribution differed significantly from both before and after periods, with minimum fish density occurring at $1.8 \mathrm{~m}$ and gradually increasing with depth (Fig. 5).

\section{Trial 4}

Fish densities were only recorded during 2 treatment periods in the fourth trial due to equipment malfunction. Temperature and salinity distributions differed significantly between the tarpaulin treatment period and the period after (Fig. 4). During the tarpaulin treatment, minimum fish densities occurred in the top $4 \mathrm{~m}$ and increased sharply to maximum density at $6 \mathrm{~m}$. After the tarpaulin treatment, minimum fish density occurred at the surface and increased with depth (Fig. 5).

\section{DISCUSSION}

\section{Behavioural responses}

When at the surface, surrounding the cage perimeter with a tarpaulin quickly and consistently reduced

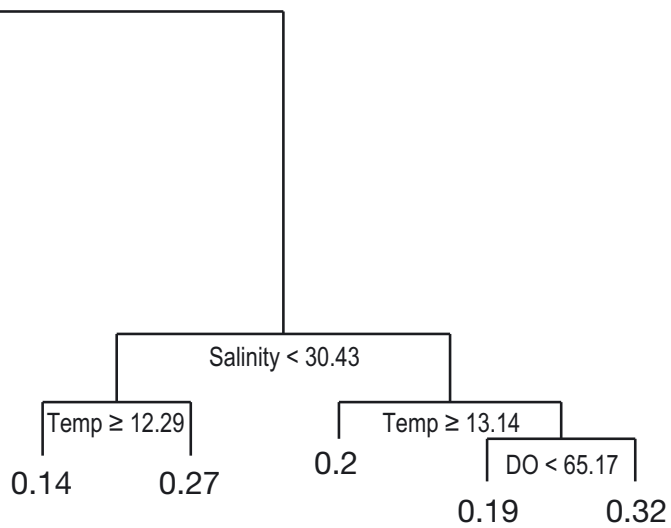

Fig. 3. Regression tree of relative Atlantic salmon Salmo salar density as a function of salinity (ppt), temperature $\left({ }^{\circ} \mathrm{C}\right)$ and dissolved oxygen ( $\%$ saturation). At each node the variable/value causing the split is identified. Predicted relative fish density is noted at the end of each terminal branch. Branch length illustrates the reduction in relative error as a result of the previous split

DO saturations by as much as $20 \%$ within a $60 \mathrm{~min}$ period. Using this technique, our results provide evidence that salmon have some capacity to modify their behaviour in response to intermediate DO levels (59 to $78 \%$ saturation) well above the limiting oxygen saturation $\left(39 \pm 1 \%\right.$ at $12^{\circ} \mathrm{C}_{i}$ Remen et al. 2013) in a marine cage environment. In all 4 trials, vertical fish distribution shifted during the DO reduction treatment, with movement away from the depths with the lowest DO concentrations and an increase in fish density in surface waters.

However, whether salmon avoid depths within sea cages with lowest DO appears to be determined by whether a DO gradient is available within their preferred depth band based on other environmental cues, such as temperature, which override a response to intermediate DO concentrations (Oppedal et al. 2011a). With a regression tree model that included temperature, salinity and DO as predictors, the relative importance of DO in determining fish density was only $17 \%$, compared to $44 \%$ for salinity and $39 \%$ for temperature. In a more holistic model which considered all known determinants of fish distribution within sea cages, such as artificial and natural light, hunger, water current velocity and social cues, the relative influence of DO would be reduced even further.

The results of our manipulative experiment align with previous observations that salmon remained in the warm surface waters of a cage despite DO saturation being 20 to $30 \%$ lower than in the deeper, cooler water (Stien et al. 2012). During our trial, the hetero- 
geneity of the cage environment meant the width of preferred depth bands was quite small, however in environments more homogeneous in salinity and temperature, as is typical of coastal salmon farms, responses to DO may be more pronounced as they will seldom be overruled by a pycnocline.
Given that previous work on healthy Atlantic salmon suggested $70 \%$ DO saturation at $16^{\circ} \mathrm{C}$ as a threshold for reduced growth, and $60 \%$ DO saturation a threshold for fish welfare (Remen et al. 2012), we conclude that salmon have a limited capacity to align their swimming depth with DO conditions
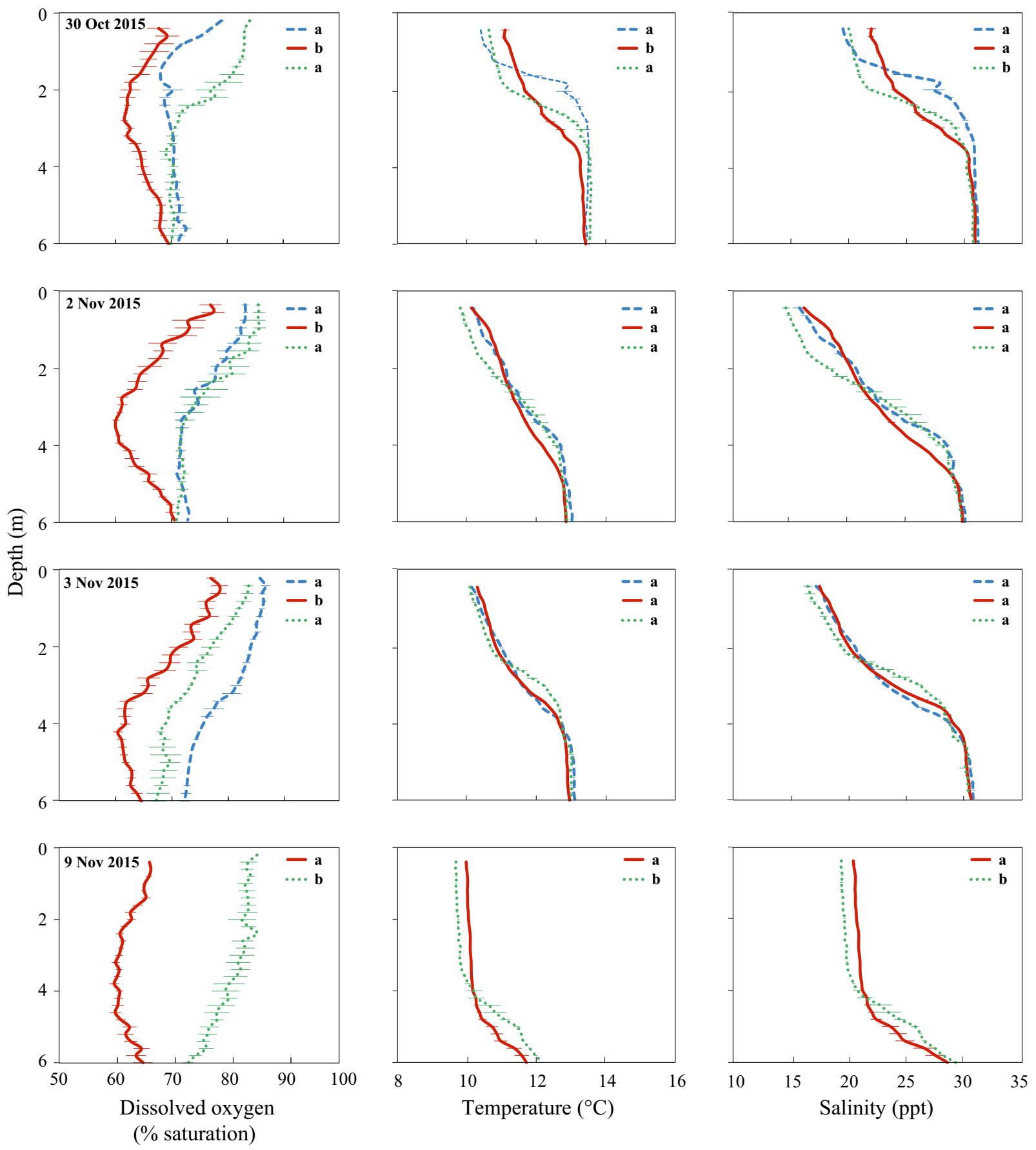

Fig. 4. Vertical profiles of dissolved oxygen (\% saturation), temperature $\left({ }^{\circ} \mathrm{C}\right)$ and salinity (ppt) in a marine aquaculture cage before tarpaulin treatment (blue line), during reduced oxygen treatment (red line) and after returning to normal conditions (green line) for each of 4 replicate trials. Values are mean \pm SE. Significant differences between treatment periods in each plot are indicated by different letters $(\mathrm{p}<0.007)$ 


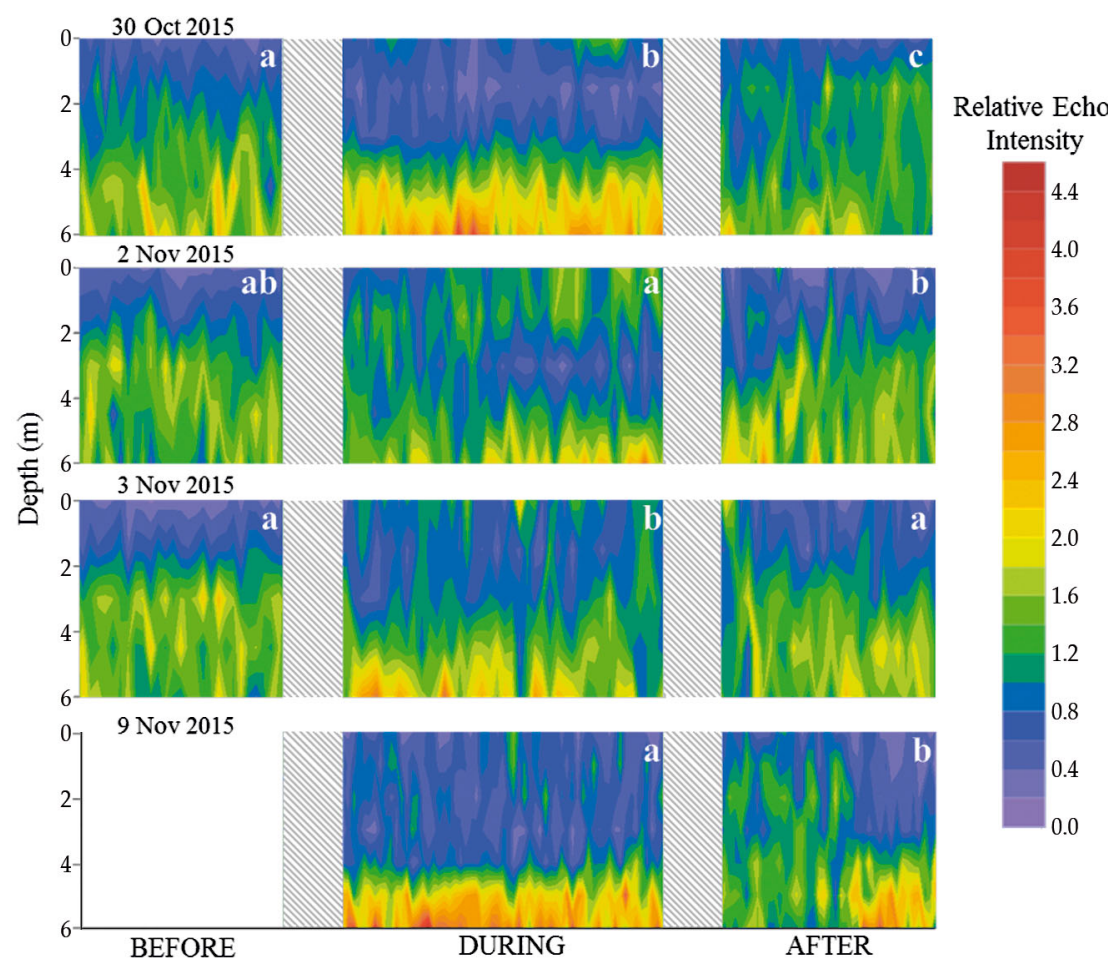

Fig. 5. Depth distribution of Atlantic salmon Salmo salar (relative echo intensity) in a marine aquaculture cage before oxygen reduction (40 min), during reduced oxygen treatment (60 min) and after returning to normal conditions (40 min) for each of 4 replicate trials. Significantly different distributions between treatment periods within each trial are indicated by different letters $(p<0.007)$. Hatching indicates transitional periods during tarp movement. On 9 Nov 2015 fish densities were only recorded during 2 treatment periods due to equipment malfunction the 4 replicate trials. Though the observed reduction in swim speed cannot be conclusively attributed to the change in DO, as it could also be related to the presence of the tarpaulin or altered social interactions as a result of the reduced fish densities, it is an interesting result for further investigation. The anadromous lifecycle of salmonids means that during some portions of their lives the fish may find themselves in rivers (Elliott et al. 1998) and estuaries (Priede et al. 1988) with low DO, little vertical stratification and no choice but to carry on. In such conditions, an increase in activity level could be lethal, whereas a reduction may allow them to survive until better conditions occur. Such an adaptation would likely contribute to the success of fish in aquaculture given that the cage environment periodically limits their ability to escape hypoxic conditions which will often improve with a changing tide (Johansson et al. 2007). which would maximize production performance. Testing responses at lower DO concentrations, such as the sustained low saturations (26 to $52 \%$ ) recently recorded on a commercial farm in Macquarie Harbour, Tasmania (Dempster et al. 2016), is required to determine if the relative importance of DO would increase with more extreme reductions in DO concentration.

With regards to swim speed, behavioural reactions of fish that encounter hypoxic conditions vary from no response to burst swimming, depending on the species and extent of hypoxia (Schurmann \& Steffensen 1994, Richards et al. 2009). Increased swim speed improves an individual's likelihood of encountering better conditions, but also increases its oxygen requirements. Alternatively, reduced swim speeds in response to hypoxia minimize the fish's oxygen requirements, but also reduces its chance of reaching more oxygenated water. In this study, a marked decrease of instantaneous swim speed was observed during the reduced DO treatment compared to both the before and after periods in 3 of

\section{Practical implications}

As global sea surface temperatures continue to rise and oxygen solubility decreases, hypoxia is expected to become a more frequent occurrence globally (IPCC 2014). The knowledge gained from our experiment stresses the importance for the aquaculture industry to continue developing mitigation and management practices which minimize the occurrence and impacts of hypoxia on farmed salmon.

Potential mitigation measures include site selection to prioritize water movement so that DO replenishment within cages is maximized (Johansson et al. 2007), and farming in deeper areas where there is increased distance between the cage bottom and decomposing organic matter in benthic sediments (Bannister et al. 2014). Frequent fallowing, which minimizes organic enrichment beneath cages, will also reduce biological oxygen demand and thus formation of deep water hypoxia (Valdemarsen et al. 2010). Further, if future research detects that salmon display more pronounced avoidance of 
depths with poor DO conditions when other environmental factors are uniform, then selection of locations with more vertically homogenous temperatures and salinities could minimize the need for intervention.

Preliminary work has partially tested the benefits of supplemental aeration (Srithongouthai et al. 2006) and oxygenation (Bergheim et al. 2006) in marine net cages. While these techniques improve DO conditions within cages at some depths and in some conditions, further study and cost-benefit analyses are required to optimize performance and assess feasibility at full commercial scale.

Finally, the use of environmental stimuli to alter fish distribution within cages has proven very successful (Oppedal et al. 2007, Bui et al. 2013, Stien et al. 2014). Underwater lighting is commonly used to delay maturation in salmon aquaculture. Recent studies have exploited lights for the secondary purpose of attracting the school to cage depths with reduced parasite load (Frenzl et al. 2014). The same technique could be used to attract salmon away from hypoxic depth layers, or through continuous movement of lights vertically at $1 \mathrm{~m} \mathrm{~min}^{-1}$ to prevent the formation of hypoxic layers by minimizing prolonged schooling at any one depth (Wright et al. 2015).

\section{CONCLUSIONS}

Fish in marine aquaculture cages are exposed to substantial environmental variation, but are spatially restricted in their ability to adapt and respond to suboptimal conditions. The impact of hypoxia depends critically on which, if any, response is undertaken. Our manipulative, field-based experiment provides evidence that Atlantic salmon are capable of altering their behaviour in response to intermediate DO concentrations by seeking out water layers with higher DO levels, and possibly with reduced activity levels, but that such responses can be overridden by other factors. These results confirm previous observationbased studies that DO is not a primary driver of Atlantic salmon distribution within marine cages (Johansson et al. 2006, 2007).

Acknowledgements. Many thanks to Tone Vågseth for technical support and Jan Harald Nordahl, Bjørn Frode Grønevik and Marita Laupsa for the heavy lifting and research farm upkeep. This experiment was conducted in accordance with the Norwegian Regulation on Animal Experimentation. The protocol was approved by the Norwegian Animal Research Authority (permit number 8260).

\section{LITERATURE CITED}

Bannister RJ, Valdemarsen T, Hansen PK, Holmer M, Ervik A (2014) Changes in benthic sediment conditions under an Atlantic salmon farm at a deep, well-flushed coastal site. Aquacult Environ Interact 5:29-47

* Bergheim A, Gausen M, Næss A, Hølland PM, Krogedal P, Crampton V (2006) A newly developed oxygen injection system for cage farms. Aquacult Eng 34:40-46

Bjordal Å, Juell JE, Lindem T, Femö A (1993) Hydroacoustic monitoring and feeding control in cage rearing of Atlantic salmon (Salmo salar L.) In: Reinertsen H, Dahle LA, Jørgensen L, Tvinnereim K (eds) Fish farming technology. AA Balkema, Rotterdam, p 203-208

*Bown DT, Aday DD, Rice JA (2015) Responses of coastal largemouth bass to episodic hypoxia. Trans Am Fish Soc 144:655-666

Bui S, Oppedal F, Korsøen ØJ, Sonny D, Dempster T (2013) Group behavioural responses of Atlantic salmon (Salmo salar L.) to light, infrasound and sound stimuli. PLOS ONE 8:e63696

* Bui S, Oppedal F, Stien L, Dempster T (2016) Sea lice infestation level alters salmon swimming depth in sea-cages. Aquacult Environ Interact 8:429-435

* Burt K, Hamoutene D, Mabrouk G, Lang C and others (2012) Environmental conditions and occurrence of hypoxia within production cages of Atlantic salmon on the south coast of Newfoundland. Aquacult Res 43:607-620

* Burt K, Hamoutene D, Perez-Casanova J, Kurt Gamperl A, Volkoff H (2013) The effect of intermittent hypoxia on growth, appetite and some aspects of the immune response of Atlantic salmon (Salmo salar). Aquacult Res 45:124-137

*Butler M, Bollens SM, Burkhalter B, Madin LP, Horgan E (2001) Mesopelagic fishes of the Arabian Sea: distribution, abundance and diet of Chauliodus pammelas, Chauliodus sloani, Stomias affinis, and Stomias nebulosus. Deep Sea Res II 48:1369-1383

* Dempster T, Juell JE, Fosseidengen JE, Fredheim A, Lader P (2008) Behaviour and growth of Atlantic salmon (Salmo salar L.) subjected to short-term submergence in commercial scale sea-cages. Aquaculture 276:103-111

Dempster T, Wright D, Oppedal F (2016) Identifying the nature, extent and duration of critical production periods for Atlantic salmon in Macquarie Harbour, Tasmania, during summer. Fisheries Research and Development Corporation report no. 2016-229-DLD. FRDC, Deakin

* Diaz RJ (2001) Overview of hypoxia around the world. J Environ Qual 30:275-281

* Elliott SR, Coe TA, Helfield JM, Naiman RJ (1998) Spatial variation in environmental characteristics of Atlantic salmon (Salmo salar) rivers. Can J Fish Aquat Sci 55: $267-280$

Frenzl B, Stien L, Cockerill D, Oppedal F and others (2014) Manipulation of farmed Atlantic salmon swimming behaviour through the adjustment of lighting and feeding regimes as a tool for salmon lice control. Aquaculture 424-425:183-188

Gruber N (2011) Warming up, turning sour, losing breath: ocean biogeochemistry under global change. Philos Trans R Soc A 369:1980-1996

*Herbert NA, Skjæraasen JE, Nilsen T, Salvanes AG, Steffensen JF (2011) The hypoxia avoidance behaviour of juvenile Atlantic cod (Gadus morhua L.) depends on the provision and pressure level of an $\mathrm{O}_{2}$ refuge. 
Mar Biol 158:737-746

Hochachka PW, Somero GN (2014) Biochemical adaptation. Princeton University Press, Princeton, NJ

IPCC (2014) Climate change 2014: synthesis report. Contribution of Working Groups I, II and III to the fifth assessment report of the Intergovernmental Panel On Climate Change. IPCC, Geneva

Johannessen S, Macdonald R (2009) Effects of local and global change on an inland sea: the Strait of Georgia, British Columbia, Canada. Clim Res 40:1-21

Johansson D, Ruohonen K, Kiessling A, Oppedal F, Stiansen JE, Kelly M, Juell JE (2006) Effect of environmental factors on swimming depth preferences of Atlantic salmon (Salmo salar L.) and temporal and spatial variations in oxygen levels in sea cages at a fjord site. Aquaculture 254:594-605

Johansson D, Juell JE, Oppedal F, Stiansen JE, Ruohonen K (2007) The influence of the pycnocline and cage resistance on current flow, oxygen flux and swimming behaviour of Atlantic salmon (Salmo salar L.) in production cages. Aquaculture 265:271-287

Johansson D, Laursen F, Fern A, Fosseidengen JE and others (2014) The interaction between water currents and salmon swimming behaviour in sea cages. PLOS ONE 9: e97635

Kramer DL (1987) Dissolved oxygen and fish behavior. Environ Biol Fishes 18:81-92

Kvamme BO, Gadan K, Finne-Fridell F, Niklasson L and others (2013) Modulation of innate immune responses in Atlantic salmon by chronic hypoxia-induced stress. Fish Shellfish Immunol 34:55-65

* Oppedal F, Juell JE, Johansson D (2007) Thermo-and photoregulatory swimming behaviour of caged Atlantic salmon: implications for photoperiod management and fish welfare. Aquaculture 265:70-81

次Oppedal F, Dempster T, Stien LH (2011a) Environmental drivers of Atlantic salmon behaviour in sea-cages: a review. Aquaculture 311:1-18

Oppedal F, Vågseth T, Dempster T, Juell JE, Johansson D (2011b) Fluctuating sea-cage environments modify the effects of stocking densities on production and welfare parameters of Atlantic salmon (Salmo salar L.). Aquaculture 315:361-368

Pihl L, Baden S, Diaz R (1991) Effects of periodic hypoxia on distribution of demersal fish and crustaceans. Mar Biol 108:349-360

Pollock M, Clarke L, Dube M (2007) The effects of hypoxia on fishes: from ecological relevance to physiological effects. Environ Rev 15:1-14

* Poulsen SB, Jensen LF, Nielsen KS, Malte H, Aarestrup K, Svendsen JC (2011) Behaviour of rainbow trout Oncorhynchus mykiss presented with a choice of normoxia and stepwise progressive hypoxia. J Fish Biol 79:969-979

Priede IG, Solbé JFLG, Nott JE, O'Grady KT, Cragg-Hine D (1988) Behaviour of adult Atlantic salmon, Salmo salar L., in the estuary of the River Ribble in relation to variations in dissolved oxygen and tidal flow. J Fish Biol 33: 133-139

Editorial responsibility: Pablo Sánchez Jerez, Alicante, Spain
Remen M, Oppedal F, Torgersen T, Imsland AK, Olsen RE (2012) Effects of cyclic environmental hypoxia on physiology and feed intake of post-smolt Atlantic salmon: initial responses and acclimation. Aquaculture 326-339: 148-155

Remen M, Oppedal F, Imsland AK, Olsen RE, Torgersen T (2013) Hypoxia tolerance thresholds for post-smolt Atlantic salmon: dependency of temperature and hypoxia acclimation. Aquaculture 416-417:41-47

* Remen M, Aas TS, Vågseth T, Torgersen T, Olsen RE, Imsland A, Oppedal F (2014) Production performance of Atlantic salmon (Salmo salar L.) postsmolts in cyclic hypoxia, and following compensatory growth. Aquacult Res 45:1355-1366

Richards JG, Farrell AP, Brauner CJ (eds) (2009) Hypoxia. Academic Press, London

* Schurmann H, Steffensen JF (1994) Spontaneous swimming activity of Atlantic cod Gadus morhua exposed to graded hypoxia at three temperatures. J Exp Biol 197:129-142

* Silva N, Vargas CA (2014) Hypoxia in Chilean Patagonian fjords. Prog Oceanogr 129:62-74

* Srithongouthai S, Endo A, Inoue A, Kinoshita K and others (2006) Control of dissolved oxygen levels of water in net pens for fish farming by a microscopic bubble generating system. Fish Sci 72:485-493

Stauffer BA, Gellene AG, Schnetzer A, Seubert EL, Oberg C, Sukhatme GS, Caron DA (2012) An oceanographic, meteorological, and biological 'perfect storm' yields a massive fish kill. Mar Ecol Prog Ser 468:231-243

* Stien LH, Nilsson J, Hevrøy EM, Oppedal F, Kristiansen TS, Lien AM, Folkedal O (2012) Skirt around a salmon sea cage to reduce infestation of salmon lice resulted in low oxygen levels. Aquacult Eng 51:21-25

Stien LH, Fosseidengen JE, Malm ME, Sveier H, Torgersen T, Wright DW, Oppedal F (2014) Low intensity light of different colours modifies Atlantic salmon depth use. Aquacult Eng 62:42-48

Therneau TM, Atkinson EJ (1997) An introduction to recursive partitioning using the RPART routines. Mayo Foundation Technical Report 61. Rochester, MN. www.mayo. edu/research/documents/biostat-61pdf/doc-10026699

* Thronson A, Quigg A (2008) Fifty-five years of fish kills in coastal Texas. Estuaries Coasts 31:802-813

*Valdemarsen T, Kristensen E, Holmer M (2010) Sulfur, carbon, and nitrogen cycling in faunated marine sediments impacted by repeated organic enrichment. Mar Ecol Prog Ser 400:37-53

*Wannamaker CM, Rice JA (2000) Effects of hypoxia on movements and behavior of selected estuarine organisms from the southeastern United States. J Exp Mar Biol Ecol 249:145-163

Whitmore CM, Warren CE, Doudoroff P (1960) Avoidance reactions of salmonid and centrarchid fishes to low oxygen concentrations. Trans Am Fish Soc 89:17-26

W Wright DW, Glaropoulos A, Solstorm D, Stien LH, Oppedal F (2015) Atlantic salmon Salmo salar instantaneously follow vertical light movements in sea cages. Aquacult Environ Interact 7:61-65

Submitted: September 14, 2016; Accepted: January 10, 2017 Proofs received from author(s): February 18, 2017 